\title{
Cerebrovascular Accidents In Myopathies
}

Dr. Farzad Fatehi MD.

Associate Professor of Neurology, Tehran University of M edical Sciences, Iran.

*Corresponding Author: Email: fatehifa@gmail.com

Several types of stroke in myopathies are described: ischemic, metabolic, or cryptogenic. Ischemic stroke may be categorized as cardioembolic, angiopathic, hemodynamic, or thrombophilic. Cardiac involvement in the form of atrial fibrillation/flutter, dilated cardiomyopathy, or non-compaction Cardioembolic could ensue in stroke. Angiopathic stroke occurs provided that there is atherosclerosis or mitochondrial disorders. Thrombophilic stroke may happen in polymyositis or dermatomyositis along with anti-phospholipid syndrome. M etabolic stroke usually manifests as stroke-like episode and is a distinct feature of various mitochondrial disorders, principally MELAS syndrome. The clinical manifestations are as a result of a vasogenic edema, demonstrating as hyperintensity on $\mathrm{T} 2$, DWI, and apparent diffusion coefficient mapping. Differentiation between ischemic and metabolic stroke is essential in terms of diagnosis, therapy, and prognosis. In conclusion, ischemic stroke attributable to cardioembolism, arteriopathy, or thrombophilia are occasional events in myopathies, but metabolic stroke is a frequent feature of mitochondrial disorders.

Key words: Cerebrovascular, stroke

DOI: $10.7575 /$ aiac.abcmed.ca1.51

Published Date: February 2017

Peer-review is under responsibility of the 9th Iranian Stroke Congress.

Published by Australian International Academic Centre, Australia

This published work is open access under the CC BY license.

Available online at www.abcmed.aiac.org.au 